\title{
A CASE OF VEGETATIVE ENDOCARDITIS, CAUSED BY AN UNIDENTIFIED PLEOMORPHIC BACTERIUM.*
}

\author{
A. M. PAPPENHEIMER AND H. H. SATCHWELL. \\ (From the Pathological Laboratory of Bellevtue Hospital, N. Y.)
}

THE case here described is of interest in that the inciting microorganism, which was present in the blood during life, presents rather remarkable characteristics, and differs, we believe, from any of the bacteria hitherto found in association with endocarditic lesions. ${ }^{x}$

\section{Ciminal RECORD.}

The patient, aged 44 years, a janitor, was admitted to the hospital July 28 , Igo6, and was under observation until his death in the hospital November 28, rgo6.

Previous history.-Has lived in New York City for $4 \mathrm{I}$ years and has worked as a janitor for $\mathrm{I}^{\frac{1}{2}}$ years; clerk for ro years before this. Heavy drinker of beer and whiskey, with frequent excesses. Chews excessively, but smokes only occasionally. One cup of coffee daily. Eats irregularly. Sleeps poorly. Bowels move once a day. Usual weight is 135 lbs. Scarlet fever when a child; good recovery. German measles at 20 years. Fifteen years ago was in a hospital for I I days, suffering from nervousness, insomnia, and vomiting (acute alcoholism?). 'Twenty-four years ago had a urethral discharge and pain on urination, lasting three months. At this time he had four sores on the penis which discharged yellow material. Under treatment these healed within a week. During the ensuing year, he had two similar attacks, with multiple sores on his penis. No history of secondary symptoms.

Present illness.-Dates back two weeks. Patient awakened one morning with dull pain in both hips; when he started to walk he also felt pain on the inner side of his left thigh. This has continued, and he has also felt feverish. No other pain. Appetite is good, bowels regular. There is no dyspnoea. For past year and a half he has had a cough at times, never accompanied by much sputum. He has had about a half-dozen night sweats. He believes he has lost some weight of late. Urination normal. No recent urethral discharges. Pain in thighs and fever are chief complaints. Upon admission: T. 103; P. r26; Resp. 22 .

Physical examination.-Patient is of medium frame, fairly well nourished and developed. Skin is pale, warm, and moist. Mucous membranes somewhat pale. No cutaneous eruptions. Lymph-nodes palpable, not enlarged. Pupils equally contracted and react normally. Tongue is narrow, pointed, moist, clean, slightly tremulous. Pulse small, slow, of good tension, regular; radial artery somewhat thickened. Apex beat not visible or palpable. Heart sounds heard with maximum intensity in 5th space, $3 \frac{1}{2}$ inches to left of median line. First sound at apex accompanied by a blowing murmur, transmitted into axilla. Basic sounds indistinct; no murmurs

* Received for publication July I 7,1907 .

- We are very greatly indebted to Drs. A. A. Smith, E. LeFevre, and R. J. Carlisle, visiting physicians to the Third Medical Division of Bellevue Hospital, for permission to transcribe the clinical records here presented. 


\section{6i8 A. M. Pappenheimer and H. H. Satchwell}

heard. Chest well developed, expansion good. Lungs within range of normal. Liver, dullness at $4^{\text {th }}$ space, flatness at 6th, extending a finger's breadth below costal margin. Edge of liver not palpable. Spleen not palpable. Abdomen not distended. No fluid, tumors, or tenderness. Tenderness on deep pressure behind trochanters; also along the course of the sciatic nerve. Patellar reflexes normal.

August 2. Since admission, temperature has been remittent between $99^{\circ}$ and 102. $+^{\circ}$. Pulse 80-90. No pain in back. General condition fair. Slight cough with purulent sputum. No tubercle bacilli in sputum. Yesterday and today, a few fine crackling râles heard on inspiration over lower part of left chest in anterior axillary line (5th space). Liver palpable a finger's breadth below costal margin-slightly tender.

August 6 . Since last note, temperature has been irregular, ranging between $\mathrm{roc}^{\circ}$ and $102^{\circ}$. Lungs negative. Systolic murmur heard all over precordial region. Maximum intensity in $3 \mathrm{~d}$ left interspace near sternum. No pain or limitation of motion in hips. General condition fair. Still has a slight cough with scanty mucoid expectoration.

August 8. First blood culture taken: sterile.

August 14. Today, temperature dropped from $102.6^{\circ}$ to $99^{\circ}$. Complains of severe pain and tenderness in calves of legs.

August 15. Temperature rose to I02. $6^{\circ}$. Lungs negative. Pains in legs persist.

August i6. Today, patient had a distinct chill lasting ro minutes, after which temperature rose to $\mathrm{IO}_{2} .2^{\circ}$. Lungs normal. Some tenderness in umbilical region. Examination of blood for malarial plasmodia negative.

August 2I. Since last note, temperature has ranged between $99^{\circ}$ and $101^{\circ}$. Pulse 78-96. General condition fair. Complains of some tenderness in both calves. No edema. Murmurs over precordium have changed. Rough systolic murmur is heard at ad right interspace, not transmitted. A similar murmur at apex, not transmitted. Lungs negative. Had a slight chill last night.

August 24. Since August 2I, temperature has been somewhat higher; shows daily remission between $100^{\circ}$ and $102^{\circ}$. Very cyanotic today. Profuse sweating. No pain in legs. Bowels constipated. Cardiac condition unchanged.

August 28. Temperature still irregular, ranging between $99^{\circ}$ and $102^{\circ}$. Cardiac condition unchanged. Lungs negative. Spleen barely palpable. Abdomen not distended, not tender. No tenderness in legs. No chill. No eruption. Slight cyanosis of fingers and lips in mornings.

September $x$ r. Since last note, temperature has ranged between $98^{\circ}$ and ror. Today patient has had chilly sensations, but no distinct chill. Very cyanotic. Complained of aching pains in shoulders. Cardiac condition unchanged. Lungs negative. Spleen palpable.

September 17. Second blood culture taken: sterile.

September 24. Temperature, pulse, and respiration continue about the same. Cardiac signs unchanged, save that murmurs are more intense. Systolic murmur present over apex has been louder during past few days than on previous note. Systolic murmur over $2 \mathrm{~d}$ right interspace persists. No pericardial murmurs heard. Lungs: a few scattered moist râles over both bases. No change in voice sounds.

I A Gram decolorizing bacillus was obtained from one of the flasks, but subcultures failed to grow. Organism was considered at the time as being probably a contaminating growth, and the culture reported as sterile. 
Appetite fair. Patient says he feels weak. No skin eruption has been noted at any time. Patient complains of some stiffness in left wrist upon awaking in the morning. No pain or tenderness in joints. Has some pain in the abdomen, which is dull in character. There is moderate distension. Spleen is still palpable and slightly tender. Stools formed, very dark. No ova present.

September 28 . Since last note, T. P. R. has ranged between the limits stated on previous notes. T. $=98^{\circ}-100.6^{\circ} ; \quad P .=7^{2-90} ; R .=r 8-24$. Patient cyanotic in the morning. Has indefinite pains in arms and legs. Left wrist slightly swollen and tender. Motion limited. No change in cardiac condition. Lungs normal. Spleen still palpable-not tender. Liver not palpable. No skin eruption. No chills, chilly sensations, or night sweats. Appetite fair. Feels very weak, and has lost flesh.

October 4. For the past four days, range of temperature has been higher, reaching IOI. $2^{\circ}$ and dropping to normal. No chills, chilly sensations, or sweats. Patient is still cyanotic in the mornings.

Systolic murmurs over apex and base still present. Apical murmur is intense, transmitted into left axilla and heard behind between scapulae. Lungs negative. On October 2, patient complained of dull pains in both shoulders and arms-had no tenderness or swelling. Appetite fair, slceps fairly well.

October ro. Temperature intermittent: $98^{\circ}-100.8^{\circ}$. Pulse $80-84$; regular. Respiration 20. Patient feels comfortable. Cyanosis, and stiffness in left wrist continue. Heart unchanged. Lungs: breath and voice sound distant over both bases. No râles heard. No tenderness along course of nerves in extremities. No edema about ankles. No eruption. Weight not taken, as patient has been continuously in bed since admission. Medication: salicylates, oil of wintergreen, tonics.

October 16. Pain in left wrist not so severe as before. T. P. R. same as on previous notes. Heart murmurs unchangcd. No petechiae. No edema of ankles. Bowels constipated.

November 8. Temperature is still remittent in character, ranging between 99-103 ${ }^{\circ}$. Complained of feeling chilly yesterday; no distinct chill. Physical condition unchanged.

November I0. Indistinct pains in left wrist. No limitation of motion or ten derness.

November x $_{5}$. Complains of aching pains with some tenderness of left wrist. Cardiac action regular. Systolic murmur at apex is louder. Rumbling diastolic murmur is heard at apex. No thrill felt. At base over aortic area, systolic still present. Faint diastolic murmur heard here and over $3^{\mathrm{d}}$ left space near sternum.

Lungs show scattered moist rales. Spleen still palpable. Fourth blood culture taken: Positive. (See bacteriological report.)

November I8. Patient complains of numbness in whole of left lower extremity. T. is $102.4^{\circ}$. P. 108. R. 20 . No edema; no ecchymosis; no eruption.

November r9. Still complains of numbness of whole left lower extremity with pain about left hip. Examination shows no edema; no pulse is obtained over dorsalis pedis artery. Extensive ecchymosis from middle of left thigh to middle of leg. Considerable tenderness below inner half of left Poupart's ligament. Some induration made out. Cardiac action regular. Pulse 96-roo. Double murmurs at base and apex still present, but not quite so distinct as on November 17 and 18 . No thrill made out at apex. Lungs show few scattered moist râles. Fifth blood culture taken: positive. (See bacteriological report.) 
November 20. T. $102^{\circ}$; P. I02; R. 22. Ecchymosis of left leg more marked sharply limited at middle of thigh. Marked change in surface temperature, i.e., from warm to cold, at line of demarcation. Sensation is entirely lost below this level. No edema. Almost complete paralysis of left lower extremity. Tenderness and induration extend along the course of the femoral vessels from Poupart's ligament to line of ecchymosis. No redness along this area. Some tenderness behind left greater trochanter. Lung signs unchanged. Heart regular. Blowing diastolic murmur at

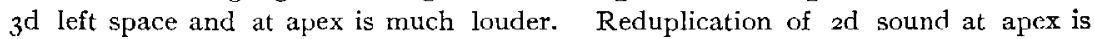
present at times.

November 2r. Patient delirious for the first time. Marked general cyanosis. Condition of left lower extremity unchanged. Cardiac murmurs unchanged; action regular. Lungs normal, except for scattcred râles.

November 22. Temperature fell from $102.8^{\circ}$ at 8 P. M. on November 21 to $97.2^{\circ}$ at 8 F. M. on November 22. Pulse g8-II2; regular. Still very delirious, general cyanosis. Ecchymosis has extended along inner side of left thigh from its middle to Poupart's ligament. Tenderness in thigh is still marked. Some tenderness and a muscular rigidity is noted in left iliac region of abdomen. Along the lowest inch of the course of the left radial artery, there is induration with apparently slight tenderness. No pulse is feit. Few small petechiae have appeared over left elbow.

November 23. T. P. R., $99^{\circ}-96-24$. Still delirious. Cyanosis is moderate. Induration along left radial artery unchanged. Condition of left lower extremity unchanged. Apparently has severe pains in left $\mathrm{lcg}$. All the toes of right foot are cold and very cyanotic. No pulse wave felt over right dorsalis pedis and posterior tibial arteries.

Cardiac action regular. Murmurs unchanged. Lungs negative, except for scattered râles.

Abdomen slightly distended. Spleen palpable. Tenderness and rigidity in left iliac region still present. No new petechial spots. Cyanosis of right foot, sharply limited above webs of toes on dorsal and plantar surfaces.

Vomited coffee-ground material yesterday. Slight cough; no expectoration.

November 24. Moderate general cyanosis. Delirium persists. Cardiac signs unchanged. Lungs scattered moist râles. Abdomen slightly distended. Tenderness in lower left quadrant.

Condition of right foot and left lower extremity unchanged. Left radial pulse not made out. Induration along the lowest inch of its course in forearm still prcsent. Skin over this area slightly reddened.

November 25. Patient died this A. M.

Urinalyses.-Examinations of the urine wcre made at intervals of a few days throughout his stay in the hospital. The total daily amount ranged between 30 and 56 ounces. A faint trace of albumin and a few hyaline and granular casts were occasionally noted. The specific gravity averaged low (I.Or3), and the urea excretion was uniformly diminished. found.

The sputum was examined on nine different occasions. No tubercle bacilli were

Examination of the feces on several occasions showed nothing of interest.

Post-Mortem Record.

Necropsy performed by Dr. Norris, $9 \frac{1}{2}$ hours post-mortem.

General appearance.-Body light, weight about $90 \mathrm{lbs}$, height $5 \mathrm{ft}$., 6 in., ema- 
TABLE I.

Blood Examinations.

\begin{tabular}{|c|c|c|c|c|c|c|c|c|c|c|}
\hline & \multirow{2}{*}{ DATE: } & \multirow{2}{*}{$\begin{array}{l}\text { FRyThRo- } \\
\text { CYTES }\end{array}$} & \multirow{2}{*}{ 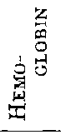 } & \multirow{2}{*}{ 惫 } & \multirow{2}{*}{ 点苔 } & \multicolumn{2}{|c|}{ LYMPHOCYTES } & \multirow{2}{*}{ 点 } & \multirow{2}{*}{$\begin{array}{c}\text { TRANSI- } \\
\text { TIONALS } \\
\text { AND LARGE, } \\
\text { MONO- } \\
\text { NUCLEARS }\end{array}$} & \multirow{2}{*}{ REMARKS } \\
\hline & & & & & & Large & Small & & & \\
\hline July & $\begin{array}{l}29 \ldots \ldots \ldots \\
28-31 \ldots \ldots\end{array}$ & $\ldots \ldots$ & $\cdots$ & $\begin{array}{r}I 7,200 \\
\ldots \ldots\end{array}$ & $\begin{array}{l}73 \\
\ldots\end{array}$ & 5 & $\begin{array}{l}\text { I4 } \\
\ldots\end{array}$ & $\begin{array}{l}\text { I } \\
\cdots\end{array}$ & 7 & No plasmodia $_{\text {"، }}$ \\
\hline Aug. & $\begin{array}{r}I \ldots \ldots \\
4 \ldots \ldots\end{array}$ & & $\ldots$ & $\begin{array}{l}24,000 \\
17,300\end{array}$ & 80 & 5 & 2.5 & 0 & $2 \cdot 5$ & No plasmodia \\
\hline$" 6$ & $7 \ldots \ldots$ & & & 18,400 & 72 & 6 & I3 & 2 & 7 & \\
\hline “ & $16 \ldots . .$. & & & 16,600 & 85 & 7 & 4 & o & 4 & No plasmodia \\
\hline$" 6$ & $24 \ldots \ldots \ldots$ & $\ldots \ldots \ldots$ & & 20,000 & $\cdots$ & $\cdots$ & $\ldots$ & $\cdots$ & $\therefore$ & \\
\hline 4 & 29. & $4.600,000$ & $60 \%$ & 14,400 & 77 & $5 \cdot 5$ & 7 & I. 5 & 8 & Basoph. $\quad \mathrm{T} \%$ \\
\hline Sept & $\begin{array}{r}8 \ldots \\
18 .\end{array}$ & $\ldots \ldots \ldots$ & $\cdots$ & $\begin{array}{l}24,600 \\
21,000\end{array}$ & . & $\cdots$ & $\cdots$ & $\cdots$ & $\cdots$ & $\cdots \cdots$ \\
\hline "act & $2.5 \ldots \ldots$ & $\ldots \ldots$ & $\ldots$ & I 4,000 & & & & & & \\
\hline Oct. & $\begin{array}{l}I \ldots \ldots \\
4 \ldots \ldots\end{array}$ & $\ddot{4,750,000}$ & $65 \%$ & $\begin{array}{l}18,000 \\
\ldots \ldots\end{array}$ & $\cdots$ & $\ldots$ & . & $\ldots$ & & \\
\hline$"$ & $10 \ldots . .$. & $\ldots \ldots \ldots$ & $\ldots$ & I 5,000 & $\ldots$ & $\ldots$ & $\ldots$ & $\ldots$ & $\ldots$ & \\
\hline 4 & 20. & $\ldots \ldots \ldots$ & 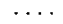 & I 2,000 & & & & & & \\
\hline 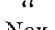 & $30 \ldots$ & $\ldots \ldots \ldots$ & $\ldots$ & I $5, \infty 00$ & 80 & 4 & J. 2 & $\cdots$ & 4 & \\
\hline Now. & I5 $5 \ldots \ldots$ & $\cdots \cdots$ & $\cdots$ & $\times 5,000$ & 80 & 6 & 13 & $\circ$ & I & \\
\hline$"$ & $\begin{array}{l}10 \ldots \ldots \ldots \\
20 \ldots \ldots \ldots\end{array}$ & & $\because$ & $\begin{array}{l}12,000 \\
\text { I } 3,200\end{array}$ & 8T & & & 0 & & \\
\hline “" & $24 \ldots$ & & $\ldots \ldots$ & 26,600 & 82 & $\begin{array}{l}3 \\
5\end{array}$ & 4 & 0 & 9 & \\
\hline
\end{tabular}

ciated, slight general icterus. The toes of the right foot, except the big toe, show bluish discoloration, and the epidermis has peeled. The toes of the left foot (ad, $3 \mathrm{~d}$, and 4 th) are slightly reddish in color; otherwise normal. Above the left knee for a distance of nine inches, there is an extensive bluish ecchymosis. No edema of the legs. Left thigh slightly larger than the right. Slight P. M. suggillation of back and shoulders. Rigor mortis marked. On the left elbow, externally, a few petcchial spots, skin over which is desiccated. Muscles are yellowish red in color, and appcar somewhat friable.

Diaphragm 5 th left space, 5 th right rib.

Liver. Right lobe at the free margin of ribs. Left lobe extends about 4 in. bencath the ensiform cartilage.

Peritoneal cavnty contains a few drachms of bile-stained fluid in the recto-vesical fossa. Ribs are not ossified.

Lungs. - No adhesions or fluid in the left pleural cavity. Both lungs emphysematous. Left lower lobe somewhat firm posteriorly. In the upper part of the lower lobe, a small reddish infarct is present. On section, the lower lobe, is slightly granular, and in places there are small areas of lobular pneumonia.

Bronchi are slightly hyperemic, congested, and contain yellowish, frothy fuid in small amount. Bronchial lymph nodes are anthracotic, without cvidence of tuberculosis.

There are about 750 c.c. of turbid bilc-staincd fluid in the right pleural cavity.

There is a considerable amount of ochre-colored fibrin between the fissures of the lobcs of the right lung, which are more or less adherent. Lower lobe feels solid. On scction it has a mottled appearance, granular on section and dry, and in places contains a few small yellowish foci. At the base, there is a reddish area, grumous on section, projecting from the surface (infarct). The lower half of the lobe posteriorly, is in a condition of red hepatization, section being slightly grumous. The rest of the lung is normal. 
Heart.-Pericardium contains about an ounce of extremely turbid yellowish fluid. The pericardium itself is in places slightly injected, and there are a few yellowish, small fibrin floccules. Right auricle, especially the ear, is intensely injected and thickened. Right heart is somewhat distended with dark reddish blood clots. The pulmonary artery and valves are normal. Tricuspid ring admits three fingers and

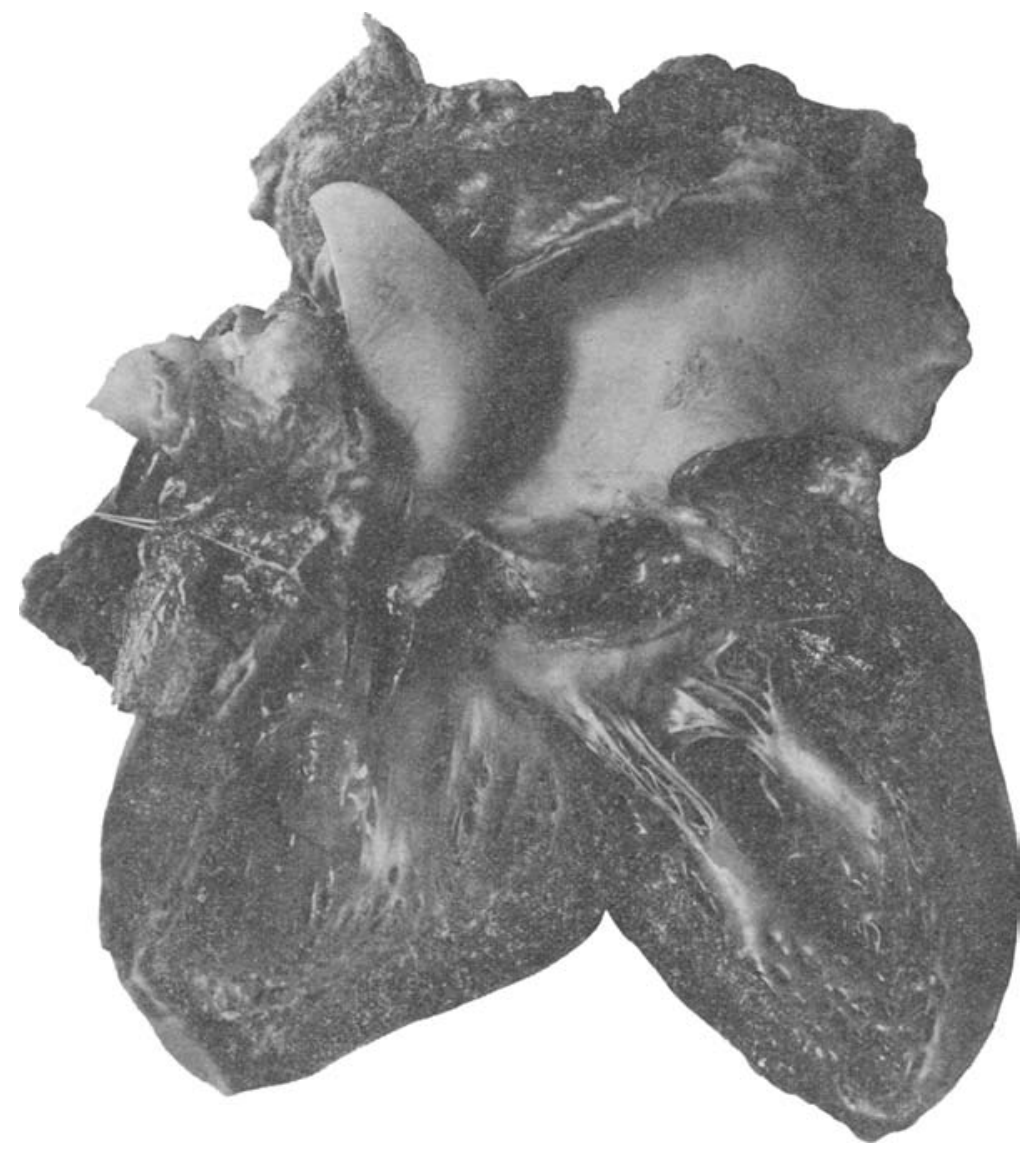

FIG. x.-Heart, reduced one-third, showing aortic vegetations.

is normal. In the right auricle, there is a softened puriform thrombus, which is firmly adherent to the auricular wall. The central portion of the clot shows whitish softening. Mitral orifice admits two fingers, the valve is slightly thickened at the edges, but is otherwise normal. Lcft ventricle of normal thickness. Right ventricle slightly stiff, but scarcely hypertrophied. Muscle is red and normal in appearance. Left auricle is normal. Its endocardium, and the endocardium of the left ventricle. is slightly opaque. The three aortic cusps are markedly thickened and adherent. On 
section, they are in places almost $\mathrm{I} \mathrm{cm}$. in thickness and are composed of a firm, dry, slightly yellowish material, in several places perhaps chalky. The left posterior cusp, at its base, shows a small tear or ulceration. The right posterior is the seat of a firm mass of tissue, and in the sinus above this cusp there is a reddish clot, which is adherent to the firmer tissue, resembling that found on the cusps. The sinus shows an aneurysmal dilatation or pouch, which admits a small marble, say $25 \mathrm{~mm}$. in diameter. The aorta itself is perfectly normal. The heart as a whole is somewhat enlarged.

In the left common iliac, about $2 \mathrm{~cm}$. below the bifucration, there is a firm, adherent reddish thrombus, which completely occludes the vessel, and extends beyond its bifurcation. The external and internal iliac arteries contain a soft, reddish thrombus, which is partially adherent.

Spleen.-Adherent to the diaphragm. Weight $205 \mathrm{gms}$. Spleen is soft and contains an infarct, triangular on section, measuring $15 \times 20 \mathrm{~mm}$. There is a deep scar in the upper pole of the organ.

Pancreas.-About normal in size, and firm.

Suprarenals.-Normal.

Kidneys.-Moderate amount of perirenal fat. Left kidney weighs 105 gms. Small and firm. Cortex thin, markings indistinct. Capsule adherent, leaving a slightly granular surface. There are a number of old scars, which extend deeply through the cortex. Kidney is extremely pale.

Weight of right kidney, $150 . \mathrm{gms}$. In the upper pole, there is a mass of firm tissue, which presents a deep ochre-yellow color, about $8 \mathrm{~mm}$. in length, and extending from the cortex well into the pyramid. There are likewise a number of smaller yellowish areas adjacent to it, the rest of the kidney being similar to the left. There are a few small cysts.

Ureters and urinary bladder normal.

Prostate and testicles and cpididymes normal in size and to the touch, but were not examined.

Liver.-On pressure, no bile exudes from the papilla. Weight $1,380 \mathrm{gms}$. Surface is slightly granular, yellowish, and cuts somewhat gritty. On section color intensely yellowish and lobulations indistinct. Gall bladder contains sticky, tarry bile.

Esophagus is normal. One of the perigastric lymph nodes is hyperemic.

Stomach.-Contains an excessive amount of mucus, otherwise normal. Abdominal and thoracic aorta normal.

Intestines.-The duodenum and the upper part of the jejunum are normal. For a distance of approximately eight feet, small intestine is intensely congested. The mucous membrane is thick, and is covered with a whitish, often distinctly yellowish exudate, and in places it has the appearance of being infiltrated with pus. No superficial erosions.

The intestinal canal at this point contains considerable amount of bloody fluid. The cecum and the ascending colon contain much tarry material. The transverse and descending colon contain numcrous firm scybalae.

The lesion described above in the small intestine extends to within six fect of the ileo-cecal valve. The lower six feet of the small intestine, the cecum, and the large intestine, including the rectum, are normal.

Peyer's patches and solitary lymph nodes are unaffected. 
Brain.-Dura normal. Pia presents in places patches of opacity over the cerebrai convexity, otherwise it is normal. Brain substance anemic. In the posterior pole of the left occipital lobe, there is an area of $3 \times 5 \mathrm{~cm}$., which is composed of softened brain substance. No yellowish color is noted.

Cortex over this area is extremely firm. Vessels at the base are normal. Lateral ventricles are normal.

Analomical diagnosis.-Infective Endocarditis (Aortic); Mural Thrombus (R. auricle); Chr. Endocarditis (Aortic); Infective Aortitis of Sinus of Valsalva, with aneurysmal dilatation; Dilatation of R. Heart; Infarcts of Lung; Lobular Pneumonia (Discrete and Diffuse); Ac. Bronchitis; Sero-fibrinous Pleurisy and Pericarditis; Cirrhosis of Liver; Infarct of Spleen; Chr. Interstitial Nephritis; Thrombus of Common and Left External and Internal Iliacs; Encephalomalacia, Embolic, Infective (L. Occipital lobe); Ac. Hemorrhagic and Suppurative Enteritis.

Smears made at autopsy from the aortic vegetations showed very numerous slender threads, varying in length and thickness-some with bulbous ends, others tapering. No distinct branching. Decolorized by Gram's method. No metachromatic granules. No other bacteria seen.

Streaks and plates were made with glycerin and ascitic agar. The organism was not isolated in pure culture, transplants showing always an admixture of small Grampositive bacilli and streptococci.

A typical streptococcus was obtained in pure culture from the pleural exudate, liver, spleen, and kidney. An attempt to cultivate the iliac thrombus yielded only a few contaminating colonies. No bacteria were found in smears from the thrombus; or from the softened area in the brain. Smears from the intestinal wall showed the usual polymorphous intestinal flora.

\section{Histological Examination.}

The tissue was fixed in Orth's fluid, and imbedded in celloidin; for the demonstration of the bacteria in the tissues, prolonged staining with Löffler's alkaline methylene-blue was found satisfactory.

Aortic valves.- The aortic vegetations are composed principally of a dense, almost structureless tissue, which in places only has an indefinite fibrillar or laminated structure. Near the surface, but found also at a considerable depth within the substance of the valve, are irregular purplish clumps, stained more intensely at their periphery. Many of these have a fairly weil-defined radial arrangement, distinguishable even with the low-power objective. With the immersion lens, in sections stained with Löffler's methylene-blue, these clumps are seen to consist of dense masses of the bacilli, to be described below, which form tangled masses or colonies, but at the periphery of the clump, evince a distinct tendency to arrange themselves in sheaves or parallel to one another.

The morphology of the individuals is identical with that of the micro-organisms found in the smears from the vegetations, and in the cultures from the blood during 
life; the bulbous, irregularly stained filaments are readily made out. A few very long, wavy, distinctly branched forms are found, as well as numerous deeply stained coccoid bodies.

In one of the sections, there were to be seen scattered oval or polyhedral cells of large size, some with double nuclei, which suggested osteoblastic cells in appearance, although no typical bone trabeculae were present.

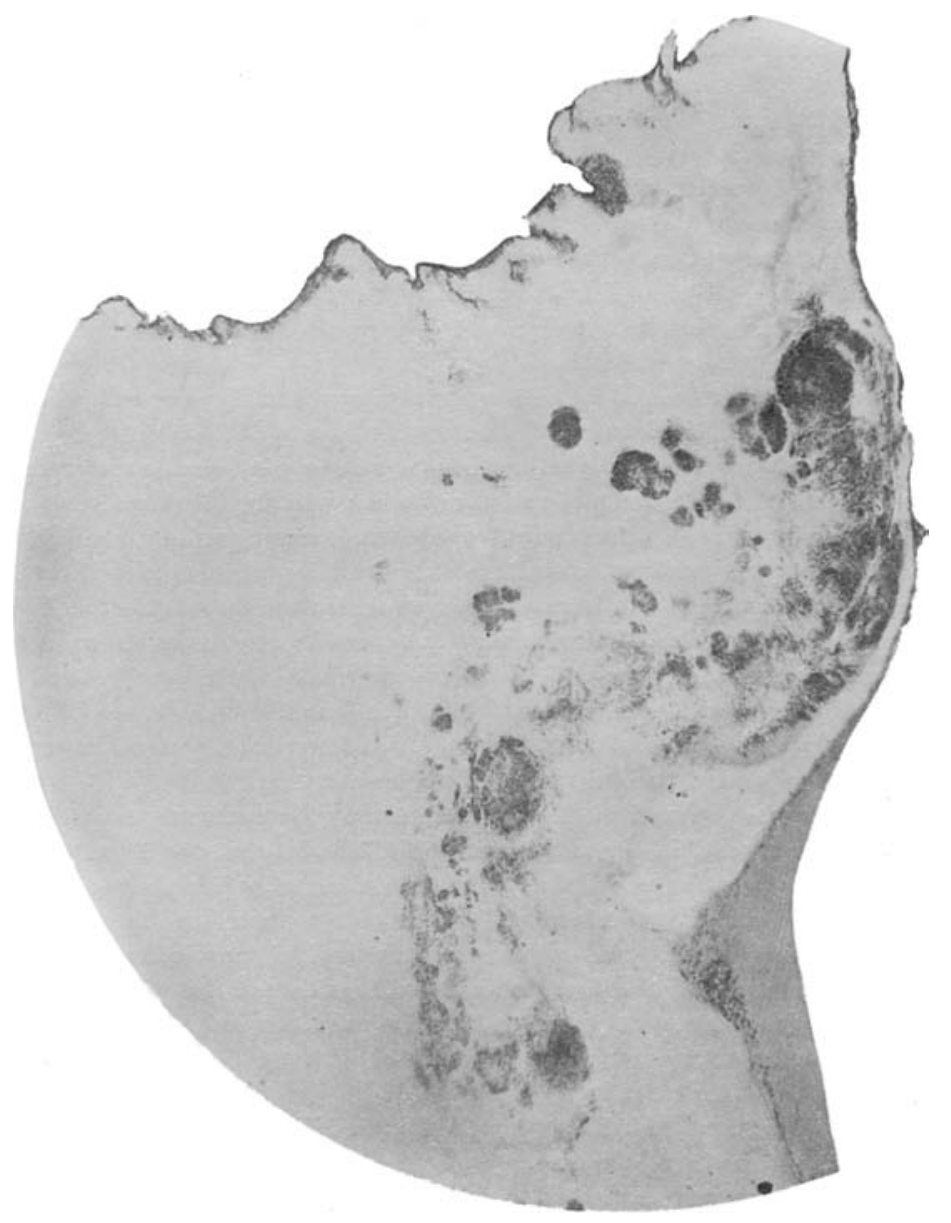

Frg. 2.-Section through aortic vegetation (low-power, Löffer methylene blue). Numerous colonies of filamentous bacilli within the depths of the vegetations.

Auricular wall and thrombus.-The thrombus is composed of red blood cells, leucocytes, chiefly polynuclears, granular, and reticulated fibrin. There is no evidence of organization. Sections stained with methylene-blue fail to show bacteria.

The myocardium, especially the papillary musculature is edematous and infi- 
trated with leucocytes. The individual fibers are swollen, their striations largely obliterated. The smaller blood-vessels show thickening of the muscular coats, and proliferation of the intima.

Iliac artery.-Sections taken through the wall of the vcsscl at the seat of the thrombus, show the lesions of an acute arteritis, involving all the coats. The endothelium is exfoliated. The internal muscular coat, especially its middle portion, is infiltrated with polynuclear leucocytes, many of them pycnotic and fragmented. The external muscular coat, and adventitia, are thickened, edematous, and infiltrated with leucocytes. The vasae vasorum are sclerotic, and there is marked perivascular round-cell infiltration. The thrombus is composed of blood-cells and hyaline fibrin, and shows no organization.

Bacteria could not be definitely demonstrated, eitber in the wall of the vessel, or in the thrombus.

Pulmonary artery.-Sections through thrombosed portion: Clot shows organization at the periphery. Endothelium is swollen. The mesarterial coat is not changed, but the adventitia is thickened, and its vessels congested. The surrounding alveoli are filled with extravasated blood.

Lung.- In sections through the hemorrhagic infarcts, the alveoli are found packed with red corpuscles. The alveolar cells are swollen, many of them exfoliated. The walls of the alveoli are not destroyed, but in places show considerable recent connective tissue formation with sprouts of cpithelioid cells projecting into the alveolar cells. In a section passing through a thrombosed vessel there is seen a partially organized clot, the ccnter of which is puriform, consisting almost wholly of polynuclear leucacytes, more or less disintegrated. No bacteria are seen within the thrombus in methyleneblue preparations. Scattered through the alveoli are isolated pairs or chains of cocci, with an occasional plump bacillus. No micro-organisms of the type isolated from the blood and present within the heart valves can be found.

Sections through the consolidated portion of left lower lobe, present the ordinary lesions of a lobar pneumonia in the stage of red hepatization.

Liver.-The lesions found in this organ are simply those of extreme passive congestion. The liver cells, in the central portion of the lobules, are shrunken, their cytoplasm is granular and eosinophilic. Their nuclei lie at the periphery of the cells, are small, and stain diffusely. Many of the liver cells contain blood pigment. The peripheral portions of the lobules in places are the seat of fatty infiltration. Some of the cells exhibit cytolytic changes, such as have been described by Oertel, I namely. solution of the hyaloplasm, with preservation of the reticulum and nuclear membrane, The hepatic capillaries are much dilated, crowded with red blood cells and leucocytes. The central veins are engorged with blood.

No bacteria are found in the sections, although cultures made at the necropsy yielded a pure growth of streptococcus.

Spleen.-Sections wcre made through the yellowish infarct and adjacent splenic tissue. The infarcted area consists of a necrotic mass staining intensely with eosin, and under high magnification is seen to be composed largely of disintegrated red blood cells. Scattercd through it are lymphoid cells and pycnotic nuclei. The margin of the infarct is formed by a cellular granulation tissue, in which arc irregular cpithelioid cells or fibroblasts, arranged with their long axis parallel to the long diameter of the infarct, lymphoid cells, new-formed capillaries, and abundant granular pigment, chiefly within larger phagocytes.

The splenic tissue itself shows the changes of chronic passive congestion. The 
blood sinuses are thickly packed with rcd corpuscles; there are many large cells filled with granular blood pigment; the endothelial cells of the sinuses appear proliferated. The Malpighian follicles are small. The trabeculae are thickened and show hyaline degeneration.

No bacteria are found in sections, either within the infarct or at its margin, or in the splenic tissue. Cultures made at autopsy, however, yielded a pure growth of Strept. pyogenes.

Kidneys.- The epithelium of the tubuli contorti is swollen, irregular and granular. The lumina contain granular detritus. The tubes of Henle and the tubuli recti are

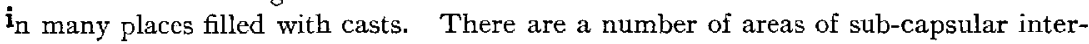
stitial inflammation. The glomeruli appear normal.

The large yellowish area noted in the gross corresponds to a necrotic infarct composed of hyaline tubules, vessels, and connective tissue. The vessels show an advanced sclerosis, thickening, and hyaline transformation of the media and adventitia.

The bright yellow color, which was a striking feature in the fresh specimen, appears to be due to the deposition of golden or yellowish-brown pigment granules (hemosiderin). In some places, especially in the cellular connective tissue at the margin of the infarct, this pigment deposit is very abundant indeed.

No bacteria are found. A pure growth of streptococci was, however, obtained at autopsy.

Adrenal.--Sections present a normal structure. The capillaries are perhaps somewhat congested.

Pancreas.-Sections of the pancreas show no noteworthy lesion. The bloodvessels everywhere are markedly congested. The acini and islands of Langerhans are entirely normal.

Small intestine.-In sections taken through that portion of the gut which in the gross showed a necrotic inflammation, the mucosa is completely exfoliated, only a few deeper acini persisting. The internal surface of the gut is formed by a thick layer of exudate, consisting of polynuclears, granular and hyaline fibrin, red blood cells, and large bacterial colonies. The submucosa is very edematous, the bloodvessels and capillaries intensely injected. The fibers of the muscularis mucosae in many places are torn apart and the purulent exudate extends into the submucous tissue. The muscular layers and peritoneum are not affected, save that the bloodvessels are intensely engorged with blood, and the intermuscular connective tissue appears edematous.

Brain.-Sections from the left occipital lobe, through area of softening: Softened tissue is composed of an edematous meshwork of neuroglia fibers, in which are newformed capillaries, and many large phagocytic cells, containing red corpuscles and blood pigment. Free unaltered red cells are found in considerable numbers. The adjacent brain tissue shows gliomatous proliferation, and there is a productive inflammation of the overlying pia-mater.

No bacteria are found in sections staincd with methylene-blue. The histological picture is therefore that of a fairly recent thrombotic softening undergoing repair.

\section{BACTERIOLOGICAL}

Reference has been made to the bacteriological examination undertaken at the necropsy, and to our failure to obtain in pure culturc the micro-organism which was present in the aortic vegeta- 
tions. The description of the cultural characters is therefore based upon a study of the micro-organism obtained upon two occasions from the circulating blood during life.

On Norember 15, a fourth blood culture was taken, the previous ones having been sterile. About 6 c.c. were withdrawn from a vein and distributed into three agar plates and one broth flask. After three days, about 25 deep and superficial colonies developed on each plate. The flask showed only a few discrete whitish colonics at the bottom, which proved to be Staph. albus.

Subcultures were made from the plate colonies on human-bloodagar slants, from which further transplants were made and the morphological and cultural features determined. A fifth blood culture, four days later, yielder a pure growth of an organism identical in all respects with that obtained from the previous culture. Fach plate showed, after 48 hours, from five to ten deep and supericial colonies; the flask remained sterile.

Morphology.-The most striking feature of the micro-organism is its pleomorphism. Pronounced variation in the length, thickness, and conformation of the individuals is constantly present, irrespective of the particular medium or stage of growth. Measurements therefore are of little value, since in every culture examined there are seen gradations from short bacillary forms, ranging from $2-6 \mu$ in length up to long filaments crossing the entire field of the immersion lens, and measuring $100 \mu$ or more in length. In hanging-drop preparations the long, threadlike forms usually exhibit more or less definite segmentation, and appear to consist of a series of individuals joined end to end. Such segmentation, however, is not always to be distinguished, even in fresh preparations, and in stained smears an interruption in the continuity of the filaments can rarely be made out.

Variation in thickness of the individuals is also well marked, slender forms about the thickncss of a tubercle bacillus perhaps predominating. The caliber is rarely uniform; frequently there is a bulbous or clublike swelling at one or both extremeties, and occasionally fusiform enlargements at one or more points along the course of the filaments. The shortest forms are usually straight, the longer ones slightly curved, and the filaments often wavy.

Branching has been observed in hanging-drop preparations from 
broth cultures, in smears from fluid and semi-solid media (Hiss-tube medium). The precise nature of this branching is difficult to study because of the tenuous character of the micro-organism, and the fact that it grows extremely slowly or not at all at room temperature. We are nevertheless of the opinion, from a careful scrutiny of hangingdrop preparations, that true branching, in the sense of a lateral budding or terminal dichotomization does not occur, but that the forked and divisional forms are produced by a process of pseudo-ramification. By this is meant that two adjacent segments becoming bent upon themselves, the sheath or membrane is ruptured at the point of juncture, and the continued growth of one segment in the line of the original axis gives rise to a forked or branched appearance.

Branches are invariably given off at the juncture of two segments, and there is usually to be made out a slight gap between the main stem and the branch. Forked forms are met with, in which the two secondary segments lie at equal angles to the primary axis. In other cases, the branch is given off at a right angle.

The significance of the distinction between true and false branching in attempting to establish the identity of the micro-organism, will be discussed later.

Staining reactions. - The organism stains readily, but not intensely, with all the usual anilin dyes. Prolonged staining with Löffler's alkaline methylene-blue or dilute carbol fuchsin has given the best pictures. In some preparations, the presence of metachromatic granules, usually two to each rod, could be readily demonstrated. Their location varied-in some individuals the granules were situated at the poles; in others, one or both were found in the central portion of the rod. The long filamentous forms frequently showed a considerable number of these granules. In iater generations, metachromatic granules, though occasionally present, were not often seen.

Very interesting pirtures were obtained in films fixed with methyl-al-ohol, and stained by Ciemsa's method. In these, the rods and filaments take a rather paleblue stain; at irregular intervals are brilliantly staincd purple granules, spherical, oval, or occasionally in the shape of short cylindrical masses with rounded ends. The terminal buibs may be pale; frequently they contain a single purple granule, and occasionally the entire bulbous enlargement takes an intense purplish stain. The purple staining substance is not invariably distributed in the form of discrete granules or rods, but the longer filaments may take a diffuse purple color over a considerable portion of their length. Frequently, the micro-organism appears to be slightly swollen in its deeper-staining portions.

The organism is readily and completely decolorized by alcohol in less than thirty seconds, when stained according to Gram's method. It is not acid fast. 
Involution forms. - A variety of irregular, swollen, and beaded forms which stain poorly, are found in old cultures. In stained smears from a dry 2o-day-old agar culture, numerous very long flamentous forms are seen, many of them showing a terminal deeply staining bulbous swelling. Whether these appearances are to be considered as involution forms associated with unfavorable conditions of growth is not clear; it is to be noted that similar forms were found in the smears made from the cardiac vegetations. In fluid media or in recent agar cultures on moist media, on the contrary, very long forms with terminal bulbous enlargements are less frequently seen.

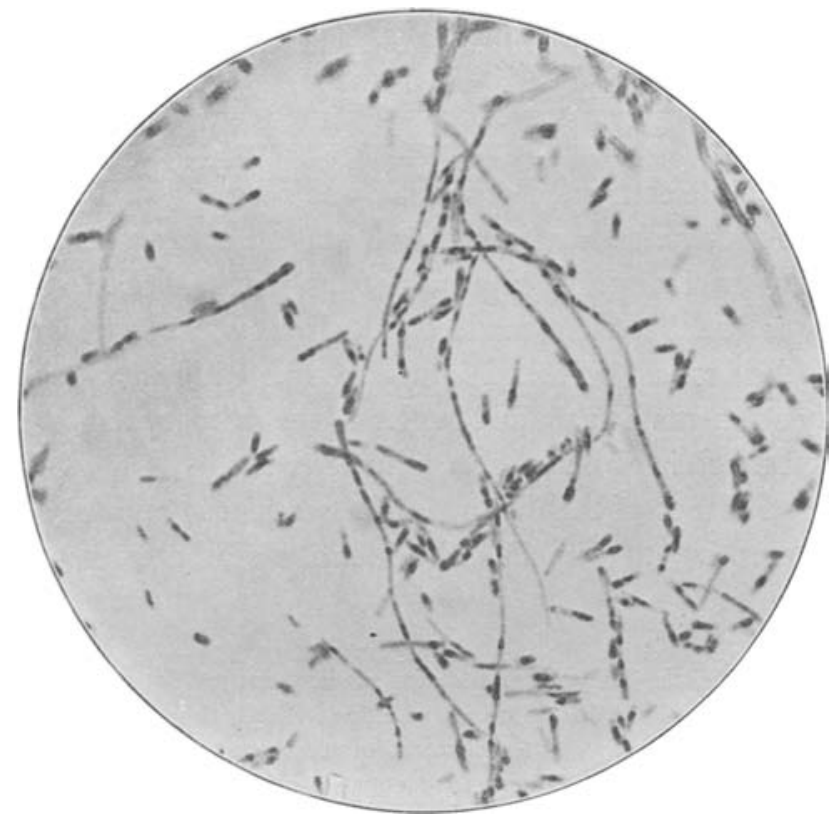

FIG. 3.-(Eleven-day agar culture, Giemsa stain, $\times$ r,000 diam.) Filamentous and bacillary forms with deeply stained chromatin substance.

It is possible that the terminal swelling may be a reaction to the mechanical resistance of the firm tissues or solid media-an explanation of which has been offered and generally accepted for the origin of the clublike terminal swellings of the actinomyces within the tissues (Lachner-Sandoval, 2 Petruschky, ${ }^{3}$ Wright4). Some of the short, greatly swollen segments resemble budding yeast cells in their appearance, and must undoubtedly be regarded as degeneration forms.

Capsules.-Films from recent agar cultures stained by Wright's method show the individual rods and filaments to be enveloped by an unstained clear space, which is bounded by a fine but distinctly stained line. The breadth of this clear space varies, but it is relatively about as large as the capsule of the Streptococcus mucosus. Such a capsule could not be constantly demonstrated, but appeared to be present whenever the cultures possessed a sticky or mucoid character. That the appearance described indicates a true capsule and not an artefact, is evidenced by the presence of numerous empty capsules. 


\section{A Case of Vegetative Endocarditis}

Films stained by Buerger's method present a similar picture, with, however, certain differences. The filaments themselves appear thicker than with Wright's stain, the clear spaces relatively narrower, and the limiting membrane, if we may use the term, less sharply defined.

The Hiss copper sulphate stain and the Welch stain gave similar, but less instructive, pictures.

Motility.-The micro-organisms are absolutely non-motile.

Spore formation.-In all cultures, but more abundantly in older growths, there

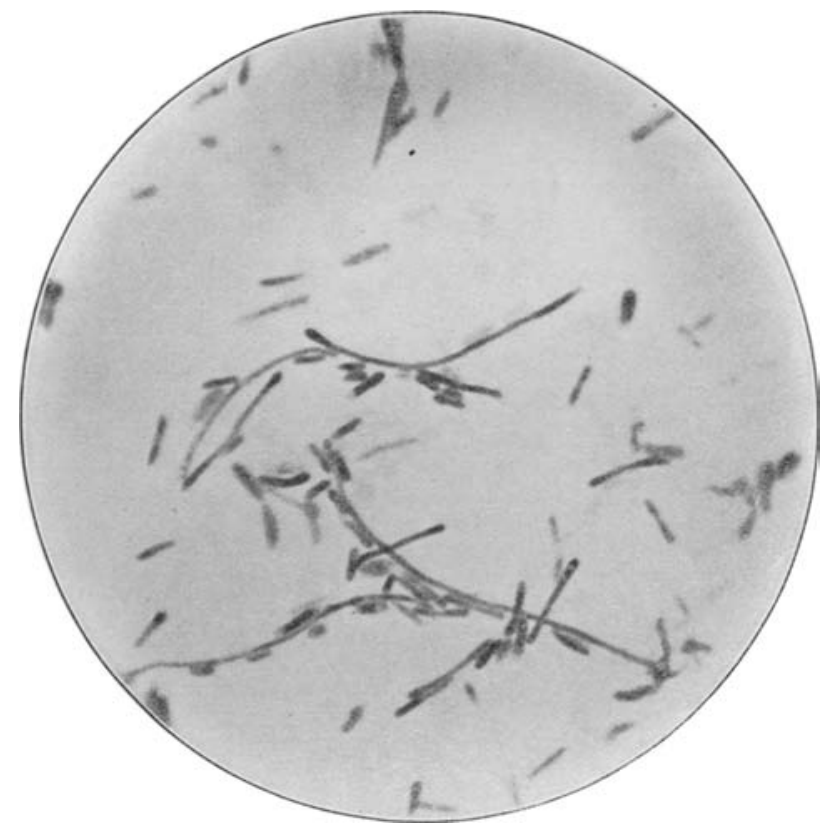

FIG. 4.-Four-day Löffler blood-serum culture. Dilute carbol fuchsin. $\chi_{1,000}$

have been noted free oval or coccoid bodies whose appearance might suggest sporeformation. We are, however, disinclined to interpret them as such, but to consider them rather, as the granular remains of disintegrating bacillary forms, since they do not respond to the ordinary spore stain, and are readily decolorized by acid and alcohol.

The globular and spheroidal masses which take a purple or nuclear stain in Giemsa preparations, we consider to represent chromatin substance rather than endospores.

An attempt was made to determine the thermal death-point of the micro-organism by suspending a recent agar culture in broth, heating to various degrees of temperature in capillary tubes, and re-transplanting on agar slants. It was, however, difficult to obtain a growth from control suspensions. The experiment was therefore unsuccessful.

Old agar cultures showing extreme thread formation were rcpeatedly examined 
for evidences of aerial spores. Chains of terminal gonidia, such as are invariably present in old cultures of streptothricae, were never observed.

Cultural characters. -The organism is an obligate-aerobe. Tubes incubated under strict anaerobic conditions (Novy apparatus) failed to show appreciable growth after II days, but grew readily when the tubes were subsequently incubated aerobically. Growth at room temperature takes place very slowly or not at all.

Broth.-The appearance varies slightly with different cultures. There is sometimes to be noted a flocculent cloud after 24 hours, near the surface of the tube, which

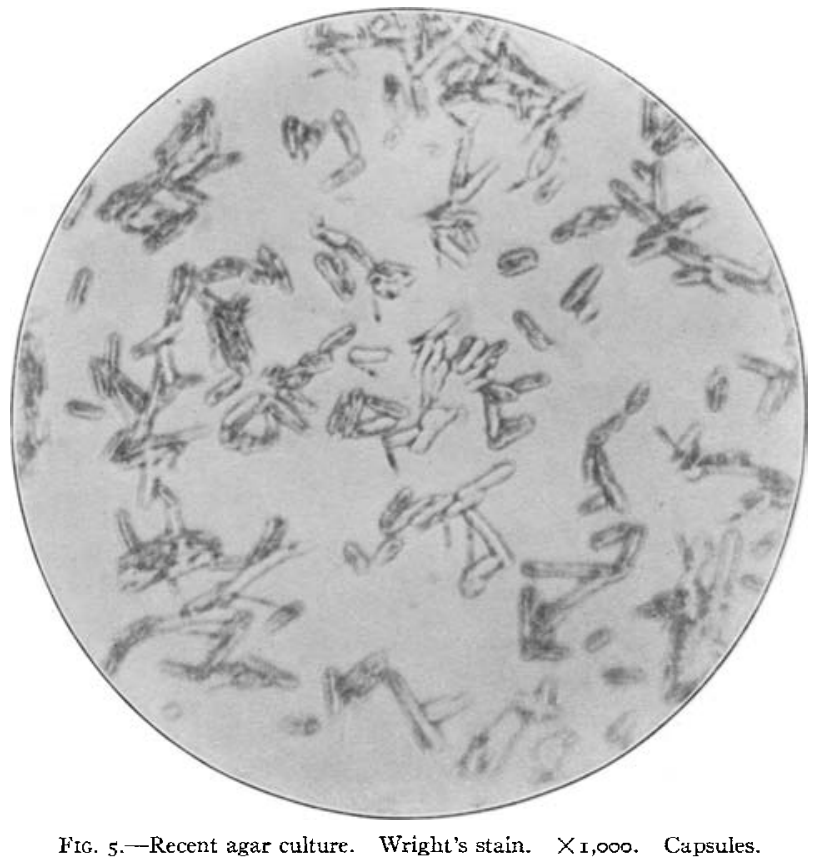

gradually settles to the bottom. After two or three days, there is seen at the bottom of the tube a delicate scaly or sandy sediment; on shaking, coarser opaque whitish granules are seen in the flocculent deposit. After prolonged transplantation the appearance of the cultures in broth has changed somewhat. After 24 hours, there appears a diffuse turbidity of the broth, with the deposition of a fine, scaly, whitish sediment along the sides and at the bottom of the tube. Further growth does not alter the appearance noticeably, save that the deposit becomes more abundant, and sediments completely as a whitish scaly deposit, leaving the supernatant broth clear. No pellicle is formed. There is no odor to the cultures.

Broth cultures tested for indol after I I days, gave a fairly marked positive reaction.

Gelatin.-No growth is observed at room temperature, even after several weeks. There is no peptonization, as shown by growing at $37^{\circ}$ and then solidifying.

Agar slants.-The organism grows readily on plain agar. After 24 hours, if a large amount has been transplanted, there appears a diffuse confluent, rather sticky, 
grayish-white growth; as the medium becomes dryer, the growth acquires a cohesive or tenacious character, so that it adheres rather firmly to the loop. As the agar dries, the surface of the growth shows a glistening, satin-like luster.

When a small amount of growth has been transplanted, discrete colonies are formed which gradually assume the appearance illustrated in Fig. 6. They attain a size not exceeding I-2 mm., are yellowish-white in color, with a slightly raised, dome-shaped central knob or projection, which appears stippled and brownish by transmitted light. The peripheral portion of the colony is Hat, the surface uneven or wrinkled, the margin irregular, finely serrated and raised slightly above the surface of the agar. The colonies have considerable cohesion, but do not adhere firmly to the medium.

Viability.--Transplants were readily obtained from agar cultures after two weeks

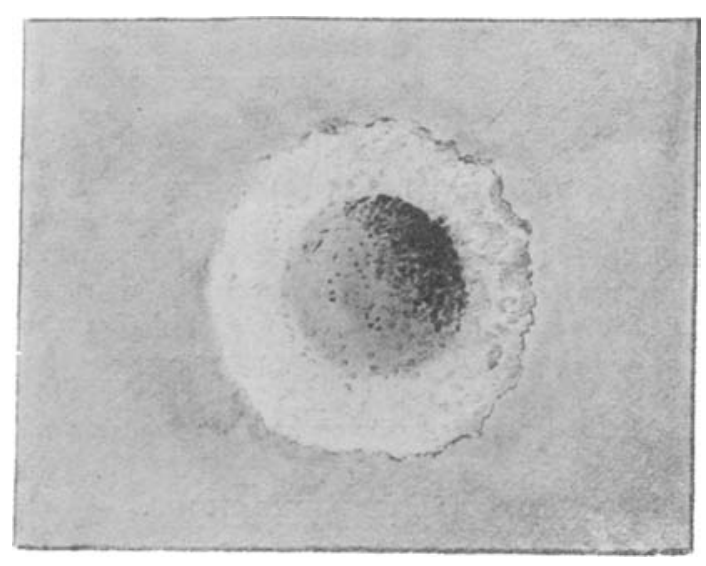

Fic. 6.-Eleven-day agar culture: single colony.

growth at incubator temperature, without special precautions against drying. No detailed study of the resistance of the micro-organism to drying was made.

Glycerin-agar slants.-The appearance of the growth is identical with that on plain agar. The organism, however, tends to die out more quickly on this medium.

Blood-agar slants. - (Human blood streaked on plain agar.) Abundant confluent growth, without striking characters.

Blood-agar plates.- Upon the four plates, obtained by blood-culture ( $\mathrm{I}-2$ c.c. of blood to Io c.c. of agar), the colonies appeared slowly, becoming visible only after 48-72 hours. The superficial colonies were $\mathrm{I}-2 \mathrm{~mm}$. in diameter, slightly raised above the surface of the medium, pearly white in color, tenacious in consistency. There was no hemolysis or discoloration of the mcdium. The maximum sizc (about $2 \mathrm{~mm}$.) was attained after four days.

Litmus milk.-No acid production or visible change in milk cultures. Smears made after three or four days show only poorly staining, apparently degenerated forms. Milk does not, therefore, appear to be a favorable medium.

Potato.-No visible growth. 
634 A. M. Pappenheimer and H. H. Satchwedi,

Hiss-tube medium (gelatin-agar + I per cent dextrose).-Grows readily along stab as whitish granular streak, somewhat more diffused near the surface. There is no clouding of the media, and no gas production.

Löffer coagulated blood serum.-Growth is not always successful. When it occurs, it appears as a moist, grayish-white confluent surface growth, with a tlocculent precipitate in the condensation water. There is no liquefaction of the serum.

Fermentation reactions.-Cultures on sugar-frce broth + I per cent saccharose, dextrose, lactose, and mannit. There is no growth in the closed arm of the tubes and no gas production. The appearance of the growth in the bulb and bend of the tube is identical with that described in ordinary broth.

Cultures on carbohydrate serum-water media. In dextrose-serum-water, there is acid production, visible after 48 hours and gradually increasing. The acid produced is not sufficient to cause coagulation of the serum. Acid is also formed in maltoseserum-water, but is produced more slowly and in less amount than in dextrose. Saccharose, lactose, mannit, dextrin, and inulin are not fermented.

Pathogenicity.-The micro-organism is non-pathogenic for guinea-pigs and rabbits.

A guinea-pig inoculated (November 19, with whole 24-hour blood-agar culture remained alive and well until March 8. It was then chloroformed. No visible lesions were found.

March 4. Three guinea-pigs were inoculated intraperitoneally with saline suspension of 48-hour agar cultures. No local reaction, or evidences of illness. Pig No $x_{2}$ inoculated with 5 c.c. of the suspension, was killed after nine days. Careful examination showed no lesions. The remaining pigs have shown no signs of illness, and are still alive.

A rabbit inoculated intraperitoneally on March 4 has remained alive and well (Jure I3, I907).

\section{GENERAL CONSIDERATIONS.}

The systematic classification of the micro-organism here described presents considerable difficulty, and we may say at the outset that we have not encountered in the literature any bacterium which closely resembles the one here studied. If we review its salient characters, we find: (I) pronounced pleomorphism; (2) tendency to the formation of long filaments, usually with terminal bulbous swellings; (3) the presence of a readily demonstrablc capsule; (4) false branching, in fluid or semi-solid media; (5) a distinct disposition toward a radial arrangement of the individuals in the tissues; (6) abundant growth upon the usual laboratory media. Negative characteristics, which are of importance in determining the systematic relationships of the micro-organism are: (I) absence of motility; (2) the probable absence of spores; (3) its failure to retain the Gram stain; (4) its strict aerobic growth; (5) its lack of pathogenicity for guinea-pigs and rabbits. 
The three groups of bacteria which would come under consideration in discussing the questions of identity are: (I) the pleomorphic bacteria - a loose term taken to include the various acidfast bacilli, the non-acid fast diphtheria group, the bacillus of glanders, the proteus group, the anaerobic B. necroseos, B. fusiformis, and other less well-known varieties; (2) the capsulated bacilli, including the Friedländer and aerogenes groups, and (3) the trichomycetes, if we adopt the term which Petruschky ${ }^{3}$ has used to include the various Actinomyces, Streptothricae, Cladothricae, and Leptothricae. With each of these three groups, the micro-organjsm which we have studied presents certain obvious affinities, and even more obvious points of difference. The extreme pleomorphism which it exhibits, and especially the constant occurrence of long filaments, differentiates it from any of the well-known members of the first group, and serves to exclude it without further comparison from the second group of capsule bacteria. Many bacteria may display a certain degree of pleomorphism, especially under unfavorable cultural conditions. With the micro-organism studicd, however, this variation in the size and configuration of the individuals is a constant and distinctive character, and on morphological grounds alone is sufficient to differentiate it, for example, from the diphtheria and pseudo-diphtheria group. To the other pleomorphic bacteria above mentioned it has even a fainter resemblance. If we attempt, therefore, for purely descriptive purposes, to group this micro-organism with the pleomorphic bacteria, it must be with the reservation that it departs in many special features from all the known varieties commonly included in the term.

The tendency of this micro-organism to grow in long filamentous forms, to develop terminal clublike swellings, and to exhibit a fairly well-marked radial arrangement in the tissues, suggests certain aflinitics to the group of Streptothricae and Actinomyces. These resemblances, nevertheless, are superficial. There are fundamentally important points of difference. The organism does not retain the Gram stain; it does not form a true mycclium, with terminal aerial spore chains; branching forms are met with only exceptionally, and true branching apparently does not occur. Other important differential characters are the rapid growth on the usual laboratory media, 
the presence of capsules, the absence of pigment production, and the character of the colonies.

The relationship of our micro-organism to the little studicd group of Leptothricae may be very bricfly considered. This group is characterized by the formation of long rigid filaments, of uniform caliber, rarely curved or wavy, and exhibiting neither branching, segmentation, nor acrial spore formation. Their mode of development is little understood, since artificial cultures have been successful in but two instances. ${ }^{5}$ Besides Leptothrix buccalis, found as a normal inhabitant of the mouth, and the closely related or identical species associated with "Mycosis of the pharynx and tonsils," and the well-known Boas-Oppler bacillus, Leptothricae have been found but a few times in association with pathological processes: in the urine of a tabetic, ${ }^{5}$ in a case of vaginitis, ${ }^{6}$ and in a gangrenous phlegmon of the lower jaw. ${ }^{7}$

In 1896 Flexner $^{8}$ discovered, in a case of puerperal endometritis in a rabbit, a filamentous bacillus which he cultivated acrobically upon sterile organs, but which did not grow upon the usual laboratory media. To this organism he gave the name $B$. pyogenes filiformis, and grouped it provisionally as a Leptothrix. In experimental lesions in rabbits, he obtained a radial or sheaflike arrangement of the filaments which resembles rather strikingly the arrangement the micro-organisms in the colonies within the aortic vegetations, in our case.

Galli-Vallerio, ${ }^{9}$ in smears and broth cultures from subcutancous tuberculous abscesses in man, found, in conjunction with the tubercle bacillus, a long threadlike organism which decolorized by Gram's method and exhibited false branching. Subcultures were unsuccessful and inoculation experiments negative. A detailed description of this bacterium, classed by the author as a Leptothrix, is not given.

As regards the group relationship of our bacterium to the Leptothricae, analogies are found only in its filamentous character and in its irregular staining. The occurrence of bulbous terminal enlargements, of false branching, of bent and wavy forms differing from the rigid, straight threads of the leptothrix, differentiate it morphologically from the hitherto described members of the group. Its 
ready growth on various media seems to us also a differential point of importance notwithstanding the unconfirmed report of Arustamoff, 5 as to the cultivation of his two species.

Without further analysis, therefore, we are led to reject the designation of leptothrix for the micro-organism which we have described.

Under the genus Cladothrix, which by $\mathrm{Kruse}^{\mathrm{xO}}$ is grouped with the Bacteriaceae, by Petruschky3 with the Hyphomycetes (sub-order Trichomycetes), three species have been described: the $C$. dichotoma (Cohn), the C. ochracea (Winogradsky), and the C. intricata (Russell). These species are obtained from water, are non-pathogenic, and do not grow readily upon laboratory media.

A number of authors, however, have described under the term "Cladothrix" micro-organisms found in necrotic or granulomatous lesions in man or animals, which upon subsequent examination by more recent workers have been included under the Streptothricae. Thus the filamentous organism described by Nocard" as Cladothrix farcinica (found in the farcin de bienf of Guadeloupe) was later shown by Sauvageau and Radais ${ }^{12}$ to exhibit true ramification and to be in all probability a true Streptothrix. So also, the Cladothrix asteroides found by Eppinger ${ }^{13}$ in a brain abscess and in the bronchial and supra-clavicular lymph-nodes, is stated by $\mathrm{Kruse}^{10}$ to show true branching and to belong rightfully to the Streptothrix group. RossiDoria, ${ }^{14}$ working with the same strain, came to a similar conclusion. Petruschky also says that "the resemblance to the Streptothricae is very close." In spite of Eppinger's direct assertion as to the occurrence of false branching, his illustrations certainly do not convey that impression. Whatever may be the proper classification for Eppinger's organism, it is readily differentiated from the one which we have studied by its warty growth on solid media, the production of ochre-colored pigment on old cultures, the reddish growth on potato with the formation of aerial spores and the behavior to Gram's stain.

The filamentous micro-organism isolated by Rosenbach ${ }^{15}$ from erysipeloid infections (erythema exudativum multiforme) and described by him as a Cladothrix is classed by Kruse, Lachner-Sandoval, Rossi-Doria, and others as a Streptothrix, and shows no resemblances to the micro-organism here described. 
In 1888 , Naunyn ${ }^{16}$ reported finding in the endocarditic vegetations from a case of chorea, and in the foci of hemorrhagic encephalitis, a branching micro-organism which was identified by Zopf as a Cladothrix or Leptothrix. Unfortunately, the original publication of Naunyn is not accessible, and the abstract in Baumgarten's Jahresberichten is too meager to permit of a comparison between this organism and ours. This is the only case, however, so far as we can ascertain, in which bacteria of this group at all resembling the one found in our case have been encountered in endocarditic processes.

The branching filamentous organism described by $\mathrm{Hesse}^{\mathrm{x}}$ in I 892 under the name Cladothrix liquefaciens, should be grouped with the Streptothricae, so also an organism isolated by Bornhaupt ${ }^{18}$ from a case of pseudo-actinomycosis in man, and identificd by him with the "Cladothrix liquefaciens" of Hesse.

Rullman' $\mathrm{S}^{\mathrm{x} 9}$ organism, probably a Streptothrix, isolated by him from the sputum in a case of pulmonary disease, shows morphological similarities, but differs very distinctly in its pathogenic and cultural characters.

In spite of the fact that no pathogenic organisms belonging beyond question to the group Cladothrix have as yet been recorded, it seems to us that the micro-organism found in our case answers to the rather ill-defined characters of this group sufficiently to consider its classification, tentatively at least, as a Cladothrix. It fully meets the salient characters of the group, if we accept the classification of Petruschky in Kolle and Wasserman's Handbuch, in so far as it exhibits a "false branching (lateral rupture of the sheath with continuation of longitudinal growth in another direction), rapid fragmentation and in consequence a bacillary character in older cultures." On the other hand, the presence of distinct capsules, and the more important fact that no micro-organism belonging with absolute certainty to the Cladothricae have as yet been found to possess pathogenic significance makes us hesitate to identify the micro-organism which we have described with this group.

Moreover, the limits of this class of trichomycetes are not sharply defined. Although Petruschky somewhat arbitrarily groups the Cladothrix under the Hyphomycetes, and sharply separated them from the higher pleomorphic bacteria, he admits that the phylogenetic 
relation is a close one. On the other hand, Neumann and Lehmann ${ }^{20}$ include the pleomorphic bacteria with the Hyphomycetes. Until a rigid and universally acceptable classification is made, we prefer not to attempt to assign a definite place to the organism studied by us, but to recognize its relationships to the pleomorphic bacteria, on the one hand, and to the Cladothrix group on the other.

To sum up, the micro-organism shows the following features: Long, slender, non-motile bacilli, showing marked pleomorphism; filamentous forms, with distinct segmentation and pseudo-ramification; irregular staining, with the presence of metachromatic granules; decolorization by mineral acids and failure to retain the Gram's stain; strict aerobic growth on all the usual laboratory media save potato; no pathogenicity for guinea-pigs and rabbits. The organism was obtained from the blood on two successive occasions, and an organism presenting identical morphology and staining reactions was present in great numbers in smears and sections of the aortic vegetations, but was not isolated in a pure culture. In the sections of the aortic vegetations, the colonies exhibited a definite and striking radial arrangement of the individual organisms.

We consider the causative relationship of this micro-organism to the production of the vegetative endocarditis to be beyond question, because of its presence in great numbers within the depths of the thrombotic deposits, and because of its presence in pure culture in the circulating blood during life. The general streptococcus infection found at autopsy, we believe to be a terminal condition, since the streptococci were not found during life in spite of repeated blood cultures, and were not present in the depths of the vegetations.

In conclusion we: wish to express our indebtedness to Dr. Norris, director of the laboratory, for his advice and assistance, and to Dr. Jaches of the Cornell University Medical School, and Mr. E. Glueck, for the photographic illustrations.

REFERENCES.

I. Oeriel, Jour. Exp. Med., igo6, 8, p. ro3.

2. LachNer-Sandoval. Ueber Strahlenpilze. Inaug. Diss., Leipzig, 1898.

3. Petruschky. "Die Pathogene Trichomyceten," Kolle u. Wassermann, Hddbch. d. path. Mikroorganismen, Jena, I903.

4. Wright, H. "The Micro-Organism of Actinomycosis," Jour. Med. Res., I9०5, I3, P. 349 . 
5. ARUStamoff. Zur Morph. u. Biol. d. Leptothrix, Wratch, i889.

6. Von HerfF. "Ueber Scheidenmykosen," Sammlung klin. Vorträge (neue Folge), I895, No. I37.

7. VoN ARx. Correspondenblz. f. Schweizer Aerzte, I899, 29, p. I6 I.

8. Flexnner. "The Bacillus Pyogenes Filiformis," etc., Jour. Exp. Med., I8g6, I, p. 2 II.

9. Galli-Valerio. Centralbl. f. Bakt., Abt. I, I905, 39, p. 234.

I0. FluEGGe. Die Mikroorganismen, Leipzig, 1896, p. Igo.

II. NoCard. "Le Farcin du Bouf de Guadeloupe," Ann. de l'Inst. Pasteur, 1888, 2, p. 293 .

I 2. Sauvageau et Radais. Ann. de l'Inst. Pasteur, I892, 6, p. 292.

I3. EPPINGer. "Ueber eine neue pathogene Streptothrix," etc., Ziegler's Bieträge z. path. Anat., 189I, 9, p. 287.

I4. Rossi-Doria. Ann. del' Inst. Sper. di Roma, I8gI.

15. Rosenbach. Arch. f. klin. Chir., 1887, 2, p. 346 .

I6. NaUnyn. Mitth. aus d. med. Klin. zu Königsberg, Leipzig, I888. p. 296. (Abstracted in Baumgarten's Jahrester., I888, 4, p. 183.)

17. Hesse. Deutsche Zeitschr. Jür Chir., 34.

18. KIESERITSKY UND BORNHAUPT. Arch. für klin. Chir., 1905, 76, p. 835 .

19. Rullman. Münch. med. Wchnschr., I898, 45, p. 919.

20. Lehman and Neumann. Atlas der Mikrnorganismen, Munich, I89g. 